\title{
Dietary indices of atherogenicity and thrombogenicity and ischaemic heart disease risk: the Caerphilly Prospective Study
}

\author{
BY A. M. FEHILY*, J. E. PICKERING, J. W. G. YARNELL AND P. C. ELWOOD \\ Medical Research Council Epidemiology Unit, Llandough Hospital, Penarth, \\ South Glamorgan CF6 IXX
}

(Received 14 August 1992 - Revised 5 April 1993-Accepted 15 April 1993)

\begin{abstract}
The aim of the study was to investigate whether proposed dietary scores of atherogenicity and thrombogenicity predict ischaemic heart disease (IHD) risk in a community sample of men aged 45-59 years. Dietary scores were calculated from consumption of various fatty acids, estimated from $7 \mathrm{~d}$ weighed intake data obtained from 665 men. Investigation of associations with blood lipids, lipoproteins and haemostatic factors revealed positive associations with low-density-lipoprotein cholesterol $(P<0.05)$ and white cell count $(P<0.05)$, and a negative association with antithrombin III $(P=0.05)$, after taking into account the effects of age, body mass index and smoking. During a 5-year follow-up period, there were twenty-one new IHD events among the 512 men in whom there was no evidence of IHD at baseline. Men with higher atherogenicity or thrombogenicity scores at baseline tended to have a higher risk of subsequent IHD. The trend was consistent but not statistically significant. A similar trend was observed for total saturates, and an inverse trend for total polyunsaturates, expressed as a percentage of total fatty acids. It is, therefore, concluded that proposed dietary indices of atherogenicity and thrombogenicity may be weak predictors of IHD risk, but that these scores are unlikely to be substantially better predictors than more simple approaches such as intakes of total saturates. To enhance the predictive ability, more complex formulas which take into account other dietary factors as well as fatty acid intakes would probably be required.
\end{abstract}

Fatty acids: Diet: Ischaemic heart disease

Two processes contribute to the development of ischaemic heart disease (IHD): atherosclerosis and thrombosis. The type of dietary fat consumed may contribute to both of these processes, some fatty acids having a greater role in atherogenesis while others have a greater role in thrombogenesis. Of the saturated fatty acids (SFA), only those with a chain length of 12,14 or $16 \mathrm{C}$ atoms have a cholesterol-raising effect and are thus atherogenic (Keys et al. 1965; Bonanome \& Grundy, 1988). SFA with a chain length of 14,16 or $18 \mathrm{C}$ atoms have been suggested to be thrombogenic (Hornstra \& Lussenberg, 1975). Both monounsaturated fatty acids (MUFA) and $n-6$ polyunsaturated fatty acids ( $n-6$ PUFA) have been shown to reduce plasma total cholesterol and low-density-lipoprotein cholesterol (LDL-C) concentrations (for review, see Gurr et al. 1989). Long chain $n-3$ polyunsaturated fatty acids ( $n-3$ PUFA) have minimal effect on plasma cholesterol level but reduce plasma triacylglycerols thromboxane $B_{2}$ and platelet activity and prolong bleeding time and heparin-thrombin clotting time (HTCT) (for review, see Burr, 1989).

In an attempt to take into account the different effects of the various fatty acids, Ulbricht \& Southgate (1991) proposed two indices which might better characterize the atherogenic

* Present address: H. J. Heinz Company Ltd, Kitt Green, Wigan, Lancashire WN5 0JL. 
and thrombogenic potential of the diet than simple approaches such as total saturates or polyunsaturated: saturated fatty acid $(P: S)$ ratio:

$$
\begin{gathered}
\text { atherogenicity }=\frac{12: 0+(4 \times 14: 0)+16: 0}{n-6 \text { PUFA }+n-3 \text { PUFA }+ \text { MUFA }}, \\
\text { thrombogenicity }= \\
\frac{14: 0+16: 0+18: 0}{(0 \cdot 5 \text { MUFA })+(0 \cdot 5 n-6 \text { PUFA })+(3 n-3 \text { PUFA })+(n-3 \text { PUFA } / n-6 \text { PUFA })} .
\end{gathered}
$$

These formulas were best estimates based on data currently available. Whether these dietary scores are predictors of IHD risk is unknown.

We have calculated both of these indices from $7 \mathrm{~d}$ weighed food intake data for a community sample of middle-aged men and found the indices to be strongly correlated ( $r$ $0 \cdot 87$, Fehily et al. 1992 a). Thus they cannot be interpreted as being indicators of separate processes. Nevertheless, this does not preclude the possibility that they may be predictors of IHD risk. The aims of our study were to investigate whether these indices are determinants of known risk factors for IHD and, more importantly, whether these indices predict risk of subsequent IHD, using data from a longitudinal study of a community sample of middle-aged men in Caerphilly, South Wales.

\section{METHODS}

The Caerphilly IHD Study is a community study of 2512 men aged 45-59 years when first seen during 1979-83. Details of the study aims, methods and response rates have been published (Caerphilly and Speedwell Collaborative Group, 1984). A representative subset (665 men) completed $7 \mathrm{~d}$ weighed food intake records. The method of weighing and calculation of nutrient intakes have been described in detail previously (Fehily et al. 1984). Fatty acid intakes were calculated using data from food composition tables (Paul et al. 1980 ) as well as data from manufacturers on the composition of spreading and cooking fats and oils and calculations from recipes.

A blood sample was taken from each subject after an overnight fast (minimum $8 \mathrm{~h}$, average $12 \mathrm{~h}$ ). Cholesterol and triacylglycerols were determined by enzymic procedures (Boehringer-Mannheim). High-density lipoprotein (HDL) was separated by precipitation with sodium phosphotungstate and $\mathrm{MgCl}_{2}$ (Lopez-Virella et al. 1977) and HDL-C then measured. Very-low-density-lipoprotein (VLDL) lipids were determined directly from a separate aliquot of plasma after ultracentrifugation in a Beckman Airfuge. LDL was calculated by difference.

Plasma fibrinogen concentration was measured nephelometrically after heat precipitation in buffered saline (Thorp et al. 1967). Plasma viscosity was determined using a Coulter viscometer (Harkness type). The heparin-neutralizing activity of platelet-poor plasma was measured using the HTCT (O'Brien et al. 1975). Antithrombin III was measured by an immunological method (Hedner \& Nilsson, 1973). Leucocyte count was measured using a Coulter counter.

Evidence of IHD at baseline (prevalent IHD) was defined as a history of severe chest pain (myocardial infarction (MI)) or angina, according to criteria provided by the London School of Hygiene and Tropical Medicine Chest Pain Questionnaire (Rose \& Blackburn, 1968), or ECG ischaemia (12-lead ECG, Minnesota codes 1-1 to 1-3, 4-1 to 4-4, 5-1 to 53 and 7-1; Rose \& Blackburn, 1968).

New IHD events occurring during 5 years of follow-up (incident IHD) were defined as (1) IHD death; deaths coded to ICD 410-414. 
(2) MI ; repeat Chest Pain Questionnaire plus Hospital Activity Analysis (HAA) were used as the basis for a detailed search of hospital notes for events which satisfied the World Health Organisation (WHO) criteria for acute MI.

(3) ECG evidence of MI; no Q/QS wave (Minnesota codes 1-1 to 1-3) on baseline ECG with major or moderate Q/QS waves (codes 1-1-1 to 1-2-5 plus 1-2-7) on the follow-up ECG.

Relationships between the atherogenicity and thrombogenicity indices and blood lipids, lipoproteins and haemostatic factors were investigated by linear regression analyses, separate regression analyses being conducted for each of the two scores. Regression coefficients were adjusted for potential confounders: age, body mass index (BMI; $\left.\mathrm{kg} / \mathrm{m}^{2}\right)$ and smoking habit.

Relationships between the indices and risk of subsequent IHD were investigated among men in whom there was no evidence of IHD at baseline. Those who already had IHD were excluded as they may have altered their diet before recruitment. For each dietary score the distribution was divided into thirds and the risk of subsequent IHD examined in each third. Results were expressed as relative odds: the relative odds for the lowest third of men were set to 1.0 and the odds of an incident IHD event in the middle and top thirds calculated relative to this. The $95 \%$ confidence intervals for the relative odds in the middle and top thirds were calculated as described by Armitage (1977).

RESLLTS

For the 665 men for whom weighed food intake data are available, the mean atherogenicity index was 0.92 (SD 0.20) and thrombogenicity index was 1.27 (SD 0.23).

Relationships between the indices and blood lipids, lipoproteins and haemostatic factors are presented in Table 1. The regression coefficients are standardized and, therefore, indicate the effect on each risk factor of a 1 SD increase in the dietary index. For example, an increase of 0.2 in the atherogenicity index was associated with an increase in plasma cholesterol of $0.05 \mathrm{mmol} / 1$. Regression coefficients were similar for both indices. All the associations were weak and few were statistically significant. LDL-C and leucocyte count were positively associated and antithrombin III was negatively associated with the indices. The proportion of variance in these risk factors which could be explained by the dietary scores was very small. For example, after taking into account the effects of age, BMI and smoking, the atherogenicity index explained only $0.70 \%$ of the variance in LDL-C and $0.52 \%$ of the variance in leucocyte count. This compares with 0.56 and $0.53 \%$ respectively for the thrombogenicity index. Entering both indices together into the multiple regression analysis had little effect on the proportion of variance explained, atherogenicity and thrombogenicity scores together explaining only $0.70 \%$ of the variance in LDL-C and $0.56 \%$ of the variance in leucocyte count. Plasma triacylglycerol concentration was the only variable examined where entering both indices together into the multiple regression analysis resulted in an increase in the proportion of variance explained: atherogenicity index explained only $0.04 \%$ of the variance in plasma triacylglycerol concentration, thrombogenicity index explained $0.13 \%$ of the variance, but both indices together explained $1.18 \%$ of the variance, the latter being statistically significant $(P<0.05)$. This is presumably because the association between atherogenicity index and triacylglycerols was weakly negative whereas that for thrombogenicity index was weakly positive.

Of the 665 men, 512 had no evidence of IHD at baseline. Among these, there were twenty-one major IHD events during 5 years of follow-up. Mean indices of those who had an IHD event during the follow-up period are compared with those of men who did not in Table 2. Both indices were slightly higher in those who went on to have an IHD event than in those who did not. The difference in the atherogenicity index represented $30 \%$ of 
Table 1. Dietary atherogenicity and thrombogenicity indices and ischaemic heart disease (IHD) risk factors among 665 men, ages 45-59 years $\uparrow$

(Values are means and standard deviations and means with their standard errors)

\begin{tabular}{|c|c|c|c|c|c|c|}
\hline & \multirow[b]{3}{*}{ Mean } & \multirow[b]{3}{*}{ SD } & \multicolumn{4}{|c|}{ Standardized regression coefficient $t_{+}^{+}$} \\
\hline & & & \multicolumn{2}{|c|}{$\begin{array}{l}\text { Atherogenicity } \\
\text { index }\end{array}$} & \multicolumn{2}{|c|}{$\begin{array}{c}\text { Thrombogenicity } \\
\text { index }\end{array}$} \\
\hline & & & Mean & SE & Mean & $\mathrm{SE}$ \\
\hline \multicolumn{7}{|l|}{ Plasma lipids (mmol/l) } \\
\hline Total cholesterol & $5 \cdot 67$ & $1 \cdot 18$ & $0 \cdot 051$ & $0 \cdot 005$ & $0 \cdot 057$ & $0 \cdot 047$ \\
\hline HDL-C & $1 \cdot 10$ & $0 \cdot 32$ & $-0 \cdot 017$ & $0 \cdot 012$ & $-0 \cdot 015$ & 0.012 \\
\hline LDL-C & $3 \cdot 76$ & $1 \cdot 07$ & $0.089 *$ & $0 \cdot 042$ & $0 \cdot 080$ & $0-043$ \\
\hline Triacylglycerols§ & $1 \cdot 66$ & & -0.011 & $0 \cdot 022$ & $0 \cdot 020$ & 0.022 \\
\hline \multicolumn{7}{|l|}{ Haemostatic factors } \\
\hline Fibrinogen $(\mathrm{g} / \mathrm{l})$ & $3 \cdot 78$ & 0.82 & -0.002 & $0 \cdot 031$ & -0.003 & 0.031 \\
\hline Viscosity $(\mathrm{cP})$ & $1 \cdot 70$ & $0 \cdot 09$ & 0.001 & $0 \cdot 004$ & $0 \cdot 004$ & 0.004 \\
\hline Heparin thrombin clotting time (s) & $30 \cdot 9$ & $12 \cdot 4$ & 0.020 & $0 \cdot 502$ & $-0 \cdot 286$ & $0 \cdot 504$ \\
\hline Antithrombin III ( $\%$ of standard) & 1042 & $19 \cdot 0$ & $-1 \cdot 131$ & 0.774 & $-1.521^{* *}$ & $0 \cdot 775$ \\
\hline Leucocyte count (cells $\left.\times 10^{\prime} / 1\right)$ & 7.03 & 1.96 & $0 \cdot 142^{*}$ & 0071 & $0 \cdot 144 *$ & 0072 \\
\hline
\end{tabular}

HDL-C, high-density-lipoprotein cholesterol; LDL-C, low-density-lipoprotein cholesterol.

* $P<0.05, * * P=0.05$.

+ For details of subjects and procedures, see pp. 250-251

* Adjusted for age, BMI and smoking habit.

$\S$ After log transformation.

Table 2. Mean atherogenicity and thrombogenicity indices and fatty acid intakes in men who had an incident ischaemic heart disease (IHD) event during 5 years of follow-up and those who did not $\dagger$

(Mean values and standard deviations)

\begin{tabular}{|c|c|c|c|c|c|}
\hline \multirow[t]{2}{*}{$n \ldots$} & \multicolumn{2}{|c|}{$\begin{array}{c}\text { No incident IHD } \\
491\end{array}$} & \multicolumn{2}{|c|}{$\begin{array}{c}\text { Incident IHD } \\
21\end{array}$} & \multirow{2}{*}{$\begin{array}{c}\text { Difference } \\
(\% \text { population SD })\end{array}$} \\
\hline & Mean & SD & Mean & $\mathrm{SD}$ & \\
\hline $\begin{array}{l}\text { Atherogenicity index } \\
\text { Thrombogenicity index }\end{array}$ & $\begin{array}{l}0.93 \\
1.28\end{array}$ & $\begin{array}{l}0 \cdot 19 \\
0.23\end{array}$ & $\begin{array}{l}0.99 \\
1.38\end{array}$ & $\begin{array}{l}0.22 \\
0.25\end{array}$ & $\begin{array}{l}+30 \\
+43^{*}\end{array}$ \\
\hline $\begin{array}{l}\text { Saturates (\% energy) } \\
\text { Monounsaturates (\% energy) } \\
\text { Polyunsaturates ( } \% \text { energy) }\end{array}$ & $\begin{array}{r}17 \cdot 3 \\
14 \cdot 5 \\
4 \cdot 9\end{array}$ & $\begin{array}{l}3 \cdot 3 \\
2 \cdot 4 \\
1 \cdot 9\end{array}$ & $\begin{array}{r}18 \cdot 1 \\
14 \cdot 9 \\
4 \cdot 4\end{array}$ & $\begin{array}{l}2 \cdot 9 \\
2 \cdot 2 \\
1 \cdot 8\end{array}$ & $\begin{array}{l}+24 \\
+17 \\
-26\end{array}$ \\
\hline $\begin{array}{l}\text { Saturates (g/ } 100 \mathrm{~g} \text { total fatty acids) } \\
\text { Monounsaturates (g/100 g total fatty acids) } \\
\text { Polyunsaturates (g/100 g total fatty acids) }\end{array}$ & $\begin{array}{l}46 \cdot 4 \\
38 \cdot 9 \\
13 \cdot 2\end{array}$ & $\begin{array}{l}4 \cdot 7 \\
2 \cdot 5 \\
4 \cdot 9\end{array}$ & $\begin{array}{l}48 \cdot 0 \\
39 \cdot 5 \\
11 \cdot 3\end{array}$ & $\begin{array}{l}4 \cdot 8 \\
2 \cdot 6 \\
3 \cdot 7\end{array}$ & $\begin{array}{l}+34 \\
+24 \\
-39\end{array}$ \\
\hline
\end{tabular}

$* P<0.05$.

$\uparrow$ For details of subjects and procedures, see pp. 250--251.

the population SD and the difference in the thrombogenicity index represented $43 \%$ of the population SD, the latter being statistically significant $(P<0.05)$.

Table 2 also displays the intakes of SFA, MUFA and PUFA, expressed as a percentage of total energy and as $\mathrm{g} / 100 \mathrm{~g}$ total fatty acids. Saturates and monounsaturates were 
Table 3. Atherogenicity, thrombogenicity and fatty acid intakes: relative odds of an ischaemic heart disease (IHD) event during 5 years of follow-up*

(Relative odds values and $95 \%$ confidence interval)

\begin{tabular}{|c|c|c|c|c|c|}
\hline \multirow[b]{2}{*}{ Dietary variable } & \multirow{2}{*}{$\begin{array}{c}\text { Lowest third } \uparrow t \\
\text { Relative } \\
\text { odds }\end{array}$} & \multicolumn{2}{|c|}{ Middle third } & \multicolumn{2}{|c|}{ Highest third } \\
\hline & & $\begin{array}{c}\text { Relative } \\
\text { odds }\end{array}$ & $95 \% \mathrm{CI}$ & $\begin{array}{l}\text { Relative } \\
\text { odds }\end{array}$ & $95 \% \mathrm{Cl}$ \\
\hline Atherogenicity index & $1 \cdot 0$ & $1 \cdot 24$ & $0.39-3.99$ & 1.61 & $0.53-4.90$ \\
\hline Thrombogenicity index & $1 \cdot 0$ & 1.57 & $0 \cdot 45 \cdot 5 \cdot 47$ & $2 \cdot 29$ & $0.70-7 \cdot 46$ \\
\hline Saturates ( $\%$ energy) & $1 \cdot 0$ & 0.84 & $0 \cdot 25-2 \cdot 81$ & 1.57 & $0.56-4.42$ \\
\hline Monounsaturates ( $\%$ energy) & $1 \cdot 0$ & 0.68 & $0 \cdot 21-2 \cdot 19$ & 1.25 & $0.45-3.43$ \\
\hline Polyunsaturates (\% energy) & $1 \cdot 0$ & $0 \cdot 44$ & $0 \cdot 15-1 \cdot 29$ & 0.48 & $0 \cdot 16-! \cdot 4 !$ \\
\hline Saturates ( $\mathrm{g} / 100 \mathrm{~g}$ total fatty acids) & $1 \cdot 0$ & $1 \cdot 47$ & $0 \cdot 47-4 \cdot 59$ & 1.49 & $0.48-4 \cdot 65$ \\
\hline Monounsaturates ( $\mathrm{g} / 100 \mathrm{~g}$ total fatty acids) & $1 \cdot 0$ & 0.54 & $0.18-1.64$ & 0.75 & $0 \cdot 27-2 \cdot 06$ \\
\hline Polyunsaturates $(\mathrm{g} / 100 \mathrm{~g}$ total fatty acids) & $1 \cdot 0$ & 0.69 & $0 \cdot 26-1 \cdot 86$ & $0 \cdot 43$ & $0 \cdot 13-1 \cdot 40$ \\
\hline
\end{tabular}

* For details of subjects and procedures, see pp. 250-251.

$\uparrow$ No. of men in each third, 156-181.

\$No. of incident IHD events in each third, 4-11.

slightly higher and polyunsaturates slightly lower among those who went on to have an incident IHD event. None of the differences were statistically significant, but those for saturates and polyunsaturates, expressed as a proportion of total fatty acids, were similar in magnitude to those for the indices.

The relative odds of an incident IHD event in each third of the dietary indices are presented in Table 3. There was a trend of increasing risk of IHD with increasing atherogenicity and thrombogenicity scores. However, the trends were not statistically significant and the $95 \%$ confidence intervals for the relative odds were wide. For comparison, the relative odds of an incident IHD event in each third of the fatty acid intake distributions are also presented. When fatty acids were expressed as a percentage of total energy, there was no evidence of an association with incident IHD. There were, however, trends of increasing risk with increasing SFA, and with decreasing PUFA when these were expressed as a percentage of total fatty acids, but these were not statistically significant.

\section{DISCUSSION}

We have demonstrated that there are weak associations between dietary indices of atherogenicity or thrombogenicity and certain IHD risk factors. We have also found some evidence to support the hypothesis that high atherogenicity or thrombogenicity scores are associated with increased risk of subsequent IHD.

The association with leucocyte count is particularly interesting, since leucocyte count has been shown to be a strong independent predictor of IHD risk in the Caerphilly and Speedwell Collaborative Heart Disease Studies (Yarnell et al. 1991) as well as in a number of other studies (Friedman et al. 1974; Grimm et al. 1985; Friedman et al. 1990). Smoking habit is a well-known determinant of leucocyte count (Zalokar et al. 1981; Hansen et al. 1990; Schwartz \& Weiss, 1991 ; Yarnell et al. 1991) and BMI may also be a determinant (Friedman et al. 1990; Schwartz \& Weiss, 1991). Our observation of a significant positive association between leucocyte count and fatty acid intake does not appear to have been reported previously. The association remains significant even after taking the effects of age, BMI and smoking habit into account. This finding is of potential importance since 
leucocytes, or more specifically neutrophils, produce substances that promote oxidation and tissue damage (Weiss, 1989) and, hence, may play a role in atherogenesis. In addition, leucocytes contain the enzyme lipoxygenase, which transforms arachidonic acid into 5hydroxyperoxy-eicosatrienoic acid (HPETE) from which leucotrienes are formed, and these possess powerful chemotactic properties (Verstraete \& Vermylen, 1984).

LDL-C, but not total cholesterol, is positively associated with atherogenicity and thrombogenicity scores. We have previously reported significant associations between both LDL-C and total cholesterol and the percentage of energy obtained from SFA (Fehily et al. 1988). A $1 \mathrm{SD}$ increase in the percentage of energy from SFA is associated with an increase in total cholesterol of $0.1 \mathrm{mmol} / 1$ and an increase in LDL-C of $0.2 \mathrm{mmol} / 1$. A $1 \mathrm{sD}$ increase in atherogenicity or thrombogenicity scores is associated with an increase of only $0.05 \mathrm{mmol} / 1$ in total cholesterol and an increase of $0.09 \mathrm{mmol} / 1 \mathrm{in} \mathrm{LDL-C}$. There are two possible reasons for the weaker associations between total and LDL-C and the atherogenicity and thrombogenicity scores. The first is that total and LDL-C may in fact be more strongly related to the percentage of energy from SFA than to the atherogenicity and thrombogenicity scores. The second possibility is that since there is presumably a greater degree of error in the estimation of intakes of individual fatty acids than in the estimation of total saturates, there is likely to be a greater degree of underestimation of associations between blood lipids and the dietary scores. Nevertheless, there is a strong positive association between both dietary scores and the percentage of energy from SFA ( $r$ 0.6, Fehily et al. 1992 a).

The only haemostatic factor showing a significant association with the thrombogenicity score is antithrombin III (inverse association). An inverse association between antithrombin III and consumption of polyunsaturates has previously been reported in Caerphilly (Rogers et al. 1988) as well as in other studies (O'Brien et al. 1976 a, b). Deficiency of antithrombin III has been reported to be associated with thrombosis, heterozygote patients suffering from congenital deficiency of antithrombin III having a high risk (Verstraete \& Vermylen, 1984). However, an independent and inverse relationship between antithrombin III and IHD risk within the general population has not been established (Yarnell et al. 1985; Meade et al. 1991).

There is no association between the dietary scores and either plasma fibrinogen or viscosity, despite the fact that the latter are strong and independent predictors of IHD risk in this population (Yarnell et al. 1991). Nevertheless, few dietary determinants of fibrinogen or viscosity have been identified. Within the Caerphilly study there is no association between these variables and the amount or type of dietary fat (Rogers et al. 1988). Furthermore, in a large, randomized, controlled trial among 2033 post-MI men (Burr et al. 1989), advice to reduce the intakes of total fat and saturates or to increase the intake of $n-6$ PUFA or $n-3$ PUFA had no effect on plasma fibrinogen or viscosity, even after 2 years.

With regard to incident IHD, our data are consistent with the hypothesis that high dietary atherogenicity or thrombogenicity scores are associated with increased risk of subsequent IHD. The magnitude of the differences is similar to those for saturates or polyunsaturates, expressed as a percentage of total fatty acids; slightly greater than those for saturates and polyunsaturates, expressed as a percentage of total energy; and greater than that for animal fat, expressed as a percentage of total energy ( $9 \%$ of the population SD; Fehily et al. 1992b).

Several other within-population cohort studies have reported the proportions of energy derived from SFA, MUFA and PUFA. However, there are considerable inconsistencies between these studies. For saturates, intakes were found to be slightly lower in those who subsequently developed IHD than in those who did not in some cohorts (Garcia-Palmieri et al. 1980; Gordon et al. 1981; Kromhout \& Coulander, 1984), but higher in others 
(Garcia-Palmieri et al. 1980; McGee et al. 1984; Kushi et al. 1985; Posner et al. 1991). Differences in mean intakes ranged from -3 to $+39 \%$ of the population sD. For monounsaturates there is no evidence of a protective effect, most studies reporting slightly higher intakes among those who went on to have an IHD event. For polyunsaturates, again there is considerable inconsistency, differences between those who subsequently developed IHD and those who did not ranging from -14 to $+28 \%$ of the population SD. In the Helsinki Study (Miettinen et al. 1982) serum phospholipids of those who subsequently developed IHD were found to contain more 16:0 and 18:0 (approximately 60\% of the SD) and less 18:2 (38\% of the SD) than controls. In two reports, data on IHD risk were presented by tertiles of fatty acid intakes: in the Western Electric Study (Shekelle et al. 1981) the relative odds of an IHD event in the top third of the saturates distribution was 1.10 and in the top third of the polyunsaturates distribution the relative odds was 0.72 ; in the study of London Busmen and Bankers (Morris et al. 1977) the relative odds of an IHD event in the top third of the animal fat distribution was 0.75 and in the top third of the $\mathrm{P}: \mathrm{S}$ ratio distribution the relative odds was $0 \cdot 31$. Two groups of researchers calculated Keys and Hegsted scores from their dietary data and both showed an increased risk of IHD with a high score (Shekelle et al. 1981; Kushi et al. 1985). These scores take into account the percentage of energy from SFA, the percentage of energy from PUFA and cholesterol intake in $\mathrm{mg} / 4184 \mathrm{~kJ}(1000 \mathrm{kcal})$. The difference between men who went on to have an IHD event and those who did not was 19 and $24 \%$ of the SD for the Keys and Hegsted score respectively (Kushi et al. 1985), and the relative odds of an IHD event in the top third of the score was 1.51 and 1.45 respectively (Shekelle et al. 1981). These are slightly lower than we have found for the atherogenicity and thrombogenicity scores.

The relative odds of an incident IHD event is 1.61 among the top third of men for atherogenicity score and 2.29 for thrombogenicity score. However, the confidence limits of the relative odds estimates are wide and the trends not statistically significant, possibly because there is only a small number of IHD events. Nevertheless, these data are extremely valuable: the Caerphilly Study is one of only two prospective studies to have used the weighed inventory method to obtain food intake data (the other being a study of 337 subjects; Morris et al. 1977), and there are few population cohort studies in which the predictive ability of these scores can be assessed.

It is concluded that the proposed dietary scores of atherogenicity and thrombogenicity may be weak predictors of IHD but that they are unlikely to be substantially better predictors than more simple approaches such as total saturates or $\mathrm{P}: \mathrm{S}$ ratios. To enhance their predictive ability, more complex formulas which take into account the effects of other dietary factors as well as fatty acids would probably be needed.

\section{REFERENCES}

Armitage, P. (1977). Statistical Methods in Medical Research, pp. 427-433. Oxford: Blackwell Scientific Publications.

Bonanome, A. \& Grundy, S. M. (1988). Effect of dietary stearic acid on plasma cholesterol level and lipoprotein levels. New England Journal of Medicine 318, 1244-1248.

Burr, M. L. (1989). Fish and the cardiovascular system. Progress in Food and Nutrition Science 13, $291-316$.

Burr, M. L., Fehily, A. M., Gilbert, J. F., Rogers, S., Holliday, R. M., Sweetnam, P. M., Elwood, P. C. \& Deadman, N. M. (1989). Effects of changes in fat, fish and fibre intakes on death and myocardial reinfarction: Diet and Reinfarction Trial (DART). Lancet 2, 757-761.

Caerphilly and Speedwell Collaborative Group (1984). Caerphilly and Speedwell collaborative heart disease studies. Journal of Epidemiology and Community Health 38, 259-262.

Fehily, A. M., Phillips, K. M. \& Sweetnam, P. M. (1984). A weighed dietary survey of men in Caerphilly, South Wales. Human Nutrition: Applied Nutrition 38A, 270-276.

Fehily, A. M., Yarnell, J. W. G., Bolton, C. H. \& Butland, B. K. (1988). Dietary determinants of blood lipids and lipoproteins: the Caerphilly study. European Journal of Clinical Nutrition 42, 405413.

Fehily, A. M., Yarnell, J. W. G., Pickering, J. \& Elwood, P. C. (1992a). Coronary heart disease and dietary factors. Lancet 339, 987-988. 
Fehily, A. M., Yarnell, J. W. G., Sweetnam, P. M. \& Elwood, P. C. (1992b). Diet and incident ischaemic heart disease: the Caerphilly study. British Journal of Nutrition 69, 303-314.

Friedman, G. D., Klatsky, A. L. \& Siegelaub, A. B. (1974). The leucocyte count as a predictor of myocardial infarction. New England Journal of Medicine 290. 1275-1278.

Friedman, G. D., Tekawa, I., Grimm, R. H., Manolio, T., Shannan, S. G. \& Sidney, S. (1990). The leucocyte count: correlates and relationship to coronary risk factors. The CARDIA study. International Journal of Epidemiology 19, 889-893.

Garcia-Palmieri, M. R., Sorlie, P., Tillotson, J., Costas, R., Cordero, E. \& Rodriguez, M. (1980). Relationship of dietary intake to subsequent coronary heart disease incidence: the Puerto Rico Heart Health Programme. American Journal of Clinical Nutrition 33, 1818-1827.

Gordon, T., Kagan, A. Garcia-Palmieri, M., Kannel, W. B., Zukel, W. J., Tillotson, J., Sorlie, P. \& Hjortland, M. (1981). Diet and its relation to coronary heart disease and death in three populations. Circulation 63 , $500-515$

Grimm, R. H. Neaton, J. D. \& Ludwig, W. (1985). Prognostic importance of the white cell count for coronary, cancer and all cause mortality. Journal of the American Medical Association 254, 1932-1937.

Gurr, M. I., Borlak, N. \& Ganatra. S. (1989). Dietary fat and plasma lipids. Nutrition Research Review's 2, $63-86$.

Hansen, L. K., Grimm, R. H. \& Neaton, J. D. (1990). The relationship of white blood cell count to other cardiovascular risk factors. International Journal of Epidemiology 19,881 888.

Hedner, U. \& Nilsson, I. M. (1973). Antithrombin III in a clinical material. Thrombosis Research 3, 631-641.

Hornstra, G. \& Lussenberg, R. N. (1975). Relationship between the type of dietary fatty acid and the arterial thrombus tendency in rats. Atherosclerosis 22, 499-516.

Keys, A., Anderson, J. T. \& Grande, F. (1965). Serum cholesterol response to changes in the diet. IV. Particular saturated fatty acids in the diet. Metabolism 14, 776-787.

Kromhout, D. \& Coulander, C. L. (1984). Dict, prevalence and 10-year mortality from coronary heart disease in 871 middle-aged men. The Zutphen study. American Joumal of Epidemiologv 119, 733-741.

Kushi, L. H., Lew, R. A.. Stare, F. J., Ellison, C. R., El Lozy, M., Bourke, G., Daly, L., Graham, I., Hickey, N., Mulcahy, R. \& Kevaney. J. (1985). Diet and 20-year mortality from coronary heart disease: the Ireland-Boston diet-heart study. New England Journal of Medicine 312, $811-818$.

Lopez-Virella, M. F., Stone, P., Ellis, S. \& Colwell, J. A. (1977). Cholesterol determination by three different methods. Clinical Chemistry 23, 882-884.

McGee, D. L., Reed, D. M., Yano, K., Kagan, A. \& Tillotson, J. (1984). Ten-year incidence of coronary heart disease in the Honolulu heart programme: relationship to nutrient intake. American Journal of Epidemiology. 119. 667-676.

Meade, T. W., Cooper, J., Miller, G. J., Howarth, D. J. \& Stirling, Y. (1991). Antithrombin III and arterial disease. Lancer 338, 850-851.

Miettinen, T. A., Naukkarinen. V., Huttunen, J. K., Mattila, S. \& Kumlin, T. (1982). Fatty acid composition of serum lipids predicts myocardial infarction. Brifish Mcdical Joumal 285, 993-995.

Morris, J. N., Marr, J. W. \& Clayton, D. G. (1977). Diet and heart: a postscript. British Medical Journal 2. $1307-1314$.

O'Brien, J. R., Etherington, M. D. \& Jamieson, S. (1976a). Acute platelet changes after large meals of saturated and unsaturated fats. Lancet 1, 878-880.

O'Brien, J. R.. Etherington, M. D., Jamieson, S. Lawford, P., Sussex, J. \& Lincoln, S. V. (1975). Heparin neutralising activity test in the diagnosis of acute myocardial infarction. Joumal of Clinical Pathology: 28. 975-979.

O'Brien, J. R., Etherington, M. D., Jamieson, S., Vergroeson, A. J. \& Ten Haar, F. T. (1976b). Effect of a diet of polyunsaturated fats on some platelet function tests. Lancet 2, 995-997.

Paul. A. A., Southgate, D. A. T. \& Russell. J. (1980). First Supplement to McCance and Widdonson's The' Composition of Foods. London: HM Stationery Office.

Posner, B. M., Cobb, J. L., Bellanger, A. J., Cupples, L. A., D'Agostino, R. B. \& Stokes, J. (1991). Dietary lipid predictors of coronary heart disease in men: the Framingham study. Archives of Internat Medicine 151 . 1181-1187.

Rogers, S., Yarnell. J. W. G. \& Fehily, A. M. (1988). Nutritional determinants of haemostatic factors in the Caerphilly study. Europesm Joumal of Clinical Nutrition 42, 197-205.

Rose, G. \& Blackburn, H. (1968). Cardiovascular Survey Methods. WHO Monograph Series, no. 56. Geneva: WHO.

Schwart7. J. \& Wciss, S. T. (1991). Host and environmental factors influencing the peripheral blood leucocyte count. American Journal of Epidemiolog.' 134, 1402-1409.

Shekelle, R. B., MacMillan Shryock, A., Paul, O., Lepper, M., Stamler, J., Liu, S. \& Raynor, W. J. (1981). Diet, serum cholesterol and death from coronary heart disease. New England Journal of Medicine 304, 65-70.

Thorp, J. M., Horsfall, G. B. \& Stone, M. C. (1967). A new red-sensitive micro-nephelometer. Medical and Biological Engineering 5, 51-..56.

Ulbricht, T. L. V. \& Southgate, D. A. T. (1991). Coronary heart disease: seven dietary factors. Lancet $\mathbf{3 3 8 ,}$ 985-992.

Verstraete, M. \& Vermylen, J. (1984). Thrombosis. Oxford: Pergamon Press. 
Weiss, S. J. (1989). Tissue destruction by neutrophils. New England Journal of Medicine 320, 365-375.

Yarnell, J. W. G., Baker, I. A., Sweetnam, P. M., Bainton, D., O'Brien, J. R., Whitehead, P. J. \& Elwood, P. C. (1991). Fibrinogen, viscosity and white cell count are major risk factors for ischaemic heart disease. The Caerphilly and Speedwell Collaborative Heart Disease Studies. Circulation 83, 836-844.

Yarnell, J. W. G., Sweetnam, P. M., Elwood, P. C., Eastham, R., Gilmour, R. A., O'Brien, J. R. \& Etherington, M. D. (1985). Haemostatic factors and ischaemic heart disease. The Caerphilly study. British Heart Journal 53, 483-487.

Zalokar, J. D., Richard, J. L. \& Clande, J. R. (1981). Leucocyte count, smoking and myocardial infarction. New England Journal of Medicine 304, 465-468. 